\title{
Ocular manifestations of Sturge-Weber syndrome: pathogenesis, diagnosis, and management
}

\author{
This article was published in the following Dove Press journal: \\ Clinical Ophthalmology \\ 13 May 2016 \\ Number of times this article has been viewed
}

\author{
Flavio Mantelli' \\ Alice Bruscolini² \\ Maurizio La Cava ${ }^{2}$ \\ Solmaz Abdolrahimzadeh ${ }^{2}$ \\ Alessandro Lambiase ${ }^{2}$ \\ 'Department of Biology, College \\ of Science and Technology, Temple \\ University, Philadelphia, PA, USA; \\ ${ }^{2}$ Department of Sense Organs, Section \\ of Ophthalmology, University of Rome \\ "Sapienza", Rome, Italy
}

\begin{abstract}
Sturge-Weber syndrome has been included in the group of phakomatoses that is characterized by hamartomas involving the brain, skin, and eyes. The characteristic facial portwine stain, involving the first branch of the trigeminal nerve and the embryonic vasculature distribution in this area, leads to several ocular complications of the anterior segment and can involve the eyelids and conjunctiva. The posterior segment of the eyes is also affected with diffuse choroidal hemangiomas. However, the most frequent ocular comorbidity is glaucoma with a prevalence rate ranging from $30 \%-70 \%$. Glaucoma is related to anterior chamber malformations, high episcleral venous pressure (EVP), and changes in ocular hemodynamics. Glaucoma can be diagnosed at birth, but the disease can also develop during childhood and in adults. The management of glaucoma in Sturge-Weber syndrome patients is particularly challenging because of early onset, frequently associated severe visual field impairment at the time of diagnosis, and unresponsiveness to standard treatment. Several surgical approaches have been proposed, but long-term prognosis for both intraocular pressure control and visual function remains unsatisfactory in these patients. Choroidal hemangiomas may also lead to visual impairment thorough exudative retinal detachment and macular edema. Treatment of exudative hemangioma complications is aimed at destructing the tumor or decreasing tumor leakage.

Keywords: Sturge-Weber syndrome, glaucoma, choroidal hemangiomas, port-wine stain, congenital disease, glaucoma surgery
\end{abstract}

\section{Introduction}

Sturge-Weber syndrome (SWS) has been included in the group of phakomatoses that includes neurofibromatosis, Klippel-Trenaunay syndrome, tuberous sclerosis, and von Hippel-Lindau syndrome. ${ }^{1}$ SWS, also known as encephalotrigeminal angiomatosis, is a condition that includes leptomemeningeal hemangioma, facial angiomatosis or nevus flammeus (also called port-wine stain [PWS]), and ocular pathological changes. ${ }^{2-5}$ The incidence of SWS is 1:50,000 infants, with no significant difference between males and females. ${ }^{6}$ No hereditary pattern or predisposition has been shown, and no malignant transformation has been demonstrated. ${ }^{7,8}$ Several genes in the 17p1-p13 region, which are known to be involved in SWS, are also known to be linked to rare abnormalities and syndromes, such as retinitis pigmentosa, cerebral astrocytoma, subglottic stenosis, Klippel-Trenaunay-Weber syndrome, and phakomatosis pigmentovascularis. ${ }^{9-13}$

The embryologic basis of SWS has been reported to be related to an impaired development of the cell precursors in the neural crest during the first embryological trimester, leading to the characteristic malformations observed in the central nervous system, skin, and eyes. ${ }^{3}$ Happle suggested that somatic mosaic mutations involving the skin cause sporadic or scattered birth defects, and the phase of embryonic development during which this occurs is fundamental. ${ }^{14}$ Shirley et al recently published a
Correspondence: Alessandro Lambiase Department of Sense Organs, Section of Ophthalmology, University of Rome "Sapienza", Viale del Policlinico I55, Rome 0016I, Italy

Tel +3906 49975837

Email alessandro.lambiase@uniroma I.it (c) (1) (8) 2016 Mantelli et al. This work is published and licensed by Dove Medical Press Limited. The full terms of this license are available at https://www.dovepress.com/terms.php cc) ${ }_{\mathrm{BY}} \mathrm{NC}$ and incorporate the Creative Commons Attribution - Non Commercial (unported, v3.0) License (http://creativecommons.org/licenses/by-nc/3.0/). By accessing the work you hereby accept the Terms. Non-commercial uses of the work are permitted without any further permission from Dove Medical Press Limited, provided the work is properly attributed. For permission for commercial use of this work, please see paragraphs 4.2 and 5 of our Terms (https://www.dovepress.com/terms.php). 
ground-breaking study where a mutation in the GNAQ gene was identified, which leads to stimulation of cell proliferation and inhibition of apoptosis. ${ }^{15}$ The authors found that the mutation is associated with both sporadic PWSs and SWS. ${ }^{15}$

Diagnosis is easily performed when the classical clinical signs of SWS are present, consisting of unilateral facial PWS along the first branch of the trigeminal nerve, hemiatrophy, progressive seizures, contralateral hemiparesis, mental deficiencies, hemianopia, and ipsilateral glaucoma. ${ }^{16}$ However, Waelchli et al showed that the PWS distribution may in fact follow the embryonic vasculature distribution of the face, rather than the trigeminal nerve. ${ }^{17}$ Neuroimaging techniques help to perform the diagnosis, showing gyriform calcifications that engage the parietal and occipital lobes, leptomeningeal angiomatosis, and astrogliosis in the brain. ${ }^{18}$ The diagnosis of SWS is based on the presence of at least two of the three manifestations of the classic triad (leptomeningeal angioma, PWS, and ocular abnormalities). However, clinical findings of SWS may vary, showing variable neural signs and symptoms with the absence of or varying ocular involvement. ${ }^{19}$

According to the clinical manifestation, SWS is classified into four types: 1) presence of brain and facial angioma, with or without glaucoma, 2) PWS without brain involvement, with or without glaucoma, 3) isolated brain angioma, usually without glaucoma, and 4) type 1 associated with systemic manifestation such as tuberous sclerosis (Table 1). ${ }^{20}$

\section{Ocular findings}

Approximately $50 \%$ of SWS patients show pathologic ocular changes, usually ipsilateral to the PWS, involving the eyelid, anterior chamber, cornea, choroid, and retina. ${ }^{3-9,13,16,19-21}$ The presence of PWS may involve the eyelid and trigger pathological alterations in the ocular blood flow. The bulbar conjunctiva (frequently at the limbus) may show diffused or localized area of pinkish discoloration related to increased conjunctival vascularization. Episcleral vessel dilatation can be observed in approximately half of SWS patients. ${ }^{21}$

Several anterior chamber changes have been described in SWS including vascular formations in the trabecular meshwork near the scleral spur surrounded by large homogeneous

Table I Classification of Sturge-Weber syndrome

\begin{tabular}{|c|c|c|c|c|}
\hline Type & $\begin{array}{l}\text { Facial } \\
\text { angioma }\end{array}$ & $\begin{array}{l}\text { Leptomenigeal } \\
\text { angioma }\end{array}$ & Glaucoma & $\begin{array}{l}\text { Systemic } \\
\text { manifestation }\end{array}$ \\
\hline Type I & + & + & \pm & \pm \\
\hline Type II & + & - & \pm & - \\
\hline Type III & - & + & \pm & - \\
\hline Type IV & + & + & \pm & + \\
\hline
\end{tabular}

Notes: +, Present; -, absent; \pm , feature can be observed but is not ubiquitous. extracellular matrix, association of the endothelial layer lining of Schlemm's canal with the basal lamina, and presence of several villi and giant vacuoles within the endothelial cells that appear as transcellular channels. ${ }^{22}$

These anatomical alterations justify the frequent development of glaucoma in $30 \%-70 \%$ of SWS patients. ${ }^{23,24}$ Glaucoma in SWS patients shows a bimodal peak of age development: an early-onset (congenital) form affecting $~ 60 \%$ of patients and a later-onset form during childhood and adolescence ( $40 \%$ of cases). ${ }^{23}$ Glaucoma in SWS is unilateral and is associated with the presence of an ipsilateral PWS, ${ }^{24}$ which most frequently involves both the eyelids (72\%) and sometimes only the upper eyelid (21\%). ${ }^{13}$ The most frequent form of glaucoma in SWS patients is open-angle glaucoma leading to progressive visual field loss. However, acute glaucoma attack due to chamber angle closure has also been described. ${ }^{25-27} \mathrm{Con}$ genital glaucoma is frequently associated with corneal changes (25\%), including haze, megalocornea, and buphthalmos. ${ }^{21}$ Other anterior segment alterations have been described in SWS patients including iris heterochromia and cataract. ${ }^{19}$

The posterior segment of the eye is also involved with hemangiomas of the choroid ( $20 \%-70 \%$ of cases $).{ }^{28}$ Choroidal hemangiomas can be clinically divided into localized and diffuse forms, but it is the diffuse form that typically occurs in SWS patients. ${ }^{19,21}$ Clinically, ophthalmoscopy shows a bright red or red-orange color appearance of the fundus, related to the increase of well-formed choroidal vessels, while hemangiomas appear as diffuse or localized areas with a dark red color and a "tomato ketchup" appearance..$^{13}$ The presence of choroidal hemangiomas is frequently asymptomatic; however, the choroid may become significantly thickened, ${ }^{29}$ and an increased risk of glaucoma development has been reported in patients with choroidal hemangioma. ${ }^{30}$

Alteration of the choroidal vessels may lead to severe retinal complications and potentially to visual loss. Subretinal hemorrhage, retinal degeneration, retinal serous detachment, photoreceptor degeneration, cystoid macular edema, macular serous detachment, tortuous retinal vessels, and optic disc coloboma have been described in SWS patients. ${ }^{21,31}$

\section{Ophthalmic management}

Routine slit lamp examination is sufficient to detect most of the alterations typically observed in SWS patients; however, if young children cannot cooperate and there is concern for visually threatening diseases such as glaucoma, examination under general anesthesia may be recquired. Anterior segment alterations include eyelids, conjunctival and episcleral hemangiomas, and corneal changes related to congenital glaucoma. Fundus examination by indirect ophthalmoscopy 
or biomicroscopy shows the typical features of choroidal hemangioma as diffuse or rarely localized areas of flat or elevated dark retina, and frequently highlights the difference in fundus color with respect to the fellow eye. Retinography may be also useful in documenting this color difference.

It is mandatory to strictly monitor glaucoma in SWS patients. Clinicians can rely on more than one parameter for diagnosing and monitoring glaucoma. In very young patients, parameters such as axial length and corneal diameter are important. Gonioscopy is a simple and useful examination to detect iridocorneal angle malformation and to orient the diagnosis toward the type of glaucoma. Intraocular pressure (IOP) measurement, optic nerve evaluation, as well as visual field testing represent the main procedures to diagnose and monitor glaucoma progression. The optic nerve head can be observed with optical coherence tomography, which is a noninvasive and relatively rapid method of evaluation in children who have difficulty in cooperating due to their young age and/or intellectual difficulty linked to diseases or syndromes such as the SWS. ${ }^{32,33}$ Visual field analysis is fundamental in evaluating glaucoma progression, but this examination can be challenging to perform in children, although with increasing age and learning more reliable results can be obtained. ${ }^{34-37}$

Several instrumental examinations may also improve the diagnosis and monitoring of choroidal hemangioma and retinal complications, especially in the presence of anterior segment opacity, such as in congenital glaucoma. Ultrasonography allows to detect choroidal alterations and to evaluate their extension, characteristics, and echogenicity. Indocyanine green angiography can add useful information on the extension and intralesional vascularity of the choroid as well as the potential detection of arterovenous shunts. Currently, the gold standard examination to characterize choroidal and retinal morphology is enhanced depth imaging spectral domain optical coherence tomography, which allows the quantification of choroidal thickness as well as the morphology and the caliber of dilated choroidal vessels. ${ }^{29,38}$ Magnetic resonance imaging may also be useful to detect broader thickening of the eyes as a consequence of diffuse choroidal hemangioma.

It is crucial to plan complete ophthalmic examinations in the follow-up of SWS patients in order to avoid visual function loss, frequently related to progressive glaucoma, and also to detect the onset of retinal complications such as exudative detachment.

\section{Glaucoma pathogenesis}

Several new hypotheses and factors have been formulated on the pathogenic mechanisms leading to the development of glaucoma, and several hypotheses have been formulated to explain the pathogenic mechanisms leading to the development of glaucoma associated with rare conditions. ${ }^{39-41}$

The main theories on the pathogenesis of glaucoma in SWS include the following:

1) A mechanical mechanism related to congenital malformation of the anterior chamber angle leading to increased resistance to aqueous humor outflow: in this case, the iris can also not have the flat anterior insertion characteristic of the congenital form; ${ }^{24}$

2) an increase in episcleral venous pressure (EVP) due to arteriovenous shunts into the episcleral hemangioma: ${ }^{29}$ this theory is based on the observation of a normal angle structure, blood within Schlemm's canal, and more severe glaucoma; ${ }^{42-44}$

3) fluid hypersecretion by either the ciliary body or the choroidal hemangioma; ${ }^{45}$ and

4) abnormal hemodynamics of the episclera and the anterior chamber angle due to premature aging of the trabecular meshwork-Schlemm's canal complex, as observed in SWS later-onset glaucoma. ${ }^{46}$

In SWS patients, an increase in EVP, as compared to normal eyes, has been reported in glaucoma-affected eyes. ${ }^{42,47}$ However, no significant difference in EVP was observed between glaucoma-affected and normal eyes in SWS patients, suggesting that elevated EVP is only a risk factor for glaucoma onset. ${ }^{47}$ Retrobulbar blood flow was also impaired in SWS patients, suggesting an increased risk to develop glaucoma with aging. However, no significant difference in the arterial retrobulbar blood flow was observed between the glaucomatous and the normal fellow normal. ${ }^{48,49}$

Glaucoma pathogenesis in SWS patients is complex, including different interlinked mechanisms that change their role with aging. Indeed, in congenital and early-onset glaucoma forms, angle malformations play a crucial role. In late-onset glaucoma, an increase in EVP, probably related to progressive hypertrophy and dilatation of the episcleral veins as reported for PWS, ${ }^{50}$ has a major pathogenic role.

A few cases of acute glaucoma attack due to angle closure have been described in SWS. Maruyama et al reported a case of a patient with SWS who developed acute glaucoma associated with posterior scleritis, edema of the ciliary body, ciliochoroidal effusion, and anterior rotation of the ciliary body. ${ }^{25}$ In this case, it was hypothesized that the ciliary body effusion induced angle closure by moving the iridolenticular diaphragm forward, which led to acute glaucoma attack. This mechanism of glaucoma induction has also been described following the use of the drug topiramate, which is used for seizures that can occur in SWS patients with leptomeningeal involvement. ${ }^{27}$ Angle-closure glaucoma in SWS has also been 
described as related to pupil block with or without ectopia lentis and pigment dispersion. ${ }^{51,52}$ In these cases, ultrasound biomicroscopy may represent a precious tool to identify and characterize the pathogenic mechanism of acute glaucoma attack. ${ }^{53}$

\section{Medical treatment of glaucoma}

The main goal of glaucoma treatment is to control IOP and to avoid progressive optic nerve damage and visual field loss. Both medical and surgical approaches have been performed to halt glaucoma progression in SWS patients (Table 2). Due to the rare nature of the disease, only small case series have been published leading to a relatively low level of evidence regarding treatment efficacy. Topical antiglaucoma drugs seem to be less efficacious in SWS patients with congenital glaucoma, while they represent first-line therapy for patients with late-onset glaucoma. ${ }^{44}$

Ong et al showed that latanoprost eye drops, as adjunctive therapy, were effective in controlling glaucoma in 50\% of 14 patients with SWS at 1 year of follow-up. ${ }^{54}$ In line with this, Yang et al demonstrated that latanoprost treatment induced a significant pressure decrease in 33\% (two eyes) of SWS glaucoma patients. ${ }^{55}$ Latanoprost acts by increasing uveoscleral outflow, theoretically bypassing the obstacle to the passage of aqueous humor due to the increase in EVP. However, long-term use of prostaglandins in SWS patients should be carefully evaluated since one of the potential side effects of these drugs is uveal effusion.

Only a few case reports describe the use of other antiglaucoma drugs in patients with SWS, suggesting that treatment with beta-blockers and carbonic anhydrase inhibitors is effective in the absence of buphthalmos. ${ }^{56}$

Wygnanski-Jaffe et al used oral propanolol for treating glaucoma in SWS patients. ${ }^{57}$ Systemic propranolol is effective in inducing reduction of hemangiomas of the skin, orbit, larynx, and eyes. ${ }^{58,59}$ However, systemic propanolol was ineffective in three of four children with SWS-related glaucoma. ${ }^{57}$

A hypothesis to justify the low efficacy of antiglaucoma drugs in controlling SWS-related glaucoma is that most of these drugs do not affect EVP, highlighting the need for novel antiglaucoma medications specifically targeting EPV.

\section{Surgical treatment of glaucoma}

Frequently, medical treatment in SWS patients is not sufficient to guarantee a good long-term control of glaucoma; therefore, surgical procedures are commonly performed in patients under 2 years of age. Goniotomy and trabeculotomy represent the most appropriate surgical procedures to overcome the malformed anterior chamber angle under 4 years of age. However, Saltzmann et al demonstrated that trabeculotomy fails to control congenital glaucoma in all

Table 2 Treatment of Sturge-Weber syndrome-associated glaucoma

\begin{tabular}{|c|c|c|c|c|c|}
\hline Author & Year & $\begin{array}{l}\text { Number } \\
\text { of patients }\end{array}$ & Type of study & Intervention & Outcome \\
\hline Basler and Sowka ${ }^{44}$ & 2011 & I & Case report & Travoprost eye drop & Good IOP control \\
\hline Sharan et $\mathrm{a}^{45}$ & 2009 & 24 & Retrospective & Medical/surgery & $\begin{array}{l}\text { Good IOP control: } 9 \text { mono- and } 9 \\
\text { multi-drug therapy; } 10 \text { trabeculectomy } \\
\text { and } 2 \text { valve implant }\end{array}$ \\
\hline Ong et $\mathrm{al}^{54}$ & 2003 & 14 & Retrospective & Latanoprost eye drop & Good IOP control in $50 \%$ at I year \\
\hline Yang et $\mathrm{al}^{55}$ & 1998 & 6 & Prospective & Latanoprost eye drop & Good IOP control in $33 \%$ \\
\hline Wygnanski-Jaffe et a $\left.\right|^{57}$ & 2015 & 4 & Prospective & Oral propranolol & $\begin{array}{l}\text { Not effective as single treatment: } \\
75 \% \text { required additional treatment }\end{array}$ \\
\hline Saltzmann et $\mathrm{al}^{60}$ & 2012 & 7 & Retrospective & Trabeculectomy-trabeculotomy & Not effective and high failure rate \\
\hline Board and Shields ${ }^{61}$ & 1981 & 5 & Case series & Trabeculectomy & Good IOP control in $20 \%$ at 6 months \\
\hline Agarwal et $\mathrm{al}^{62}$ & 1993 & 16 & Retrospective & Trabeculotomy-trabeculectomy & Good IOP control in $61 \%$ at 42 months \\
\hline Mandal $^{65}$ & 1999 & 9 & Case series & Trabeculotomy-trabeculectomy & $\begin{array}{l}\text { Good IOP control in all patients at } \\
\text { I year }\end{array}$ \\
\hline Audren et $\mathrm{al}^{67}$ & 2006 & 6 & Retrospective & Deep sclerectomy & Not effective at 26 months \\
\hline Hamush et $a^{69}$ & 1999 & 10 & Case series & Ahmed valve & Good IOP control in $30 \%$ at 60 months \\
\hline Amini et $\mathrm{al}^{70}$ & 2007 & 7 & Prospective & Molteno tube & Good IOP control in $43 \%$ at 36 months \\
\hline Naranjo-Bonilla et $\mathrm{al}^{71}$ & 2014 & I & Case report & Ex-Press ${ }^{\circledR}$ implant & Good IOP control at 10 months \\
\hline Elgin et $\mathrm{al}^{72}$ & 2007 & I & Case report & Ex-Press ${ }^{\circledast}$ implant & $\begin{array}{l}\text { Good IOP control with adjunctive } \\
\text { trabeculectomy }\end{array}$ \\
\hline Van Emelen et $\mathrm{a}^{73}$ & 2000 & 8 & Retrospective & Medical/surgery & $\begin{array}{l}\text { Good IOP control in I } 2 \% \text { with medical } \\
\text { therapy alone }\end{array}$ \\
\hline
\end{tabular}

Abbreviation: IOP, intraocular pressure. 
patients with SWS. ${ }^{60}$ These authors suggested to consider alternative surgical procedures and closer postoperative monitoring due to this significant relative risk of failure. ${ }^{60}$ One of the possible explanations of surgery failures in SWS children is that goniosurgery does not affect EVP, suggesting that pathogenic mechanisms other than the simple angle malformation influence glaucoma progression.

Other surgical approaches include filtering procedures such as trabeculectomy, posterior lip sclerotomy, ${ }^{42}$ and trabeculotomy-trabeculectomy, ${ }^{61,62}$ which bypass the alterated trabecular meshwork-Schlemm's canal complex, creating an alternative outflow passage for the aqueous humor, independent to the distal episcleral veins. However, filtering procedures have been associated with severe complications such as expulsive choroidal hemorrhage, bleeding, prolonged flat anterior chamber, and high risk of bleb failure. ${ }^{46,63}$ Intraoperative use of antimitotic agents such as mitomycin does not improve the outcome. ${ }^{64}$ Therefore, combined procedures such as trabeculotomy-trabeculectomy have been suggested as the first-line approach in infants and children. ${ }^{61,65}$

Alternative surgical procedures include nonpenetrating sclerectomy, valve drainage implants, and ciliodestructive procedures in adults. ${ }^{66,67}$ Nonpenetrating sclerotomy has been shown to have an efficacy similar to trabeculectomy in controlling SWS-related glaucoma, with a lower rate of complications ${ }^{67}$ However, in SWS patients, the presence of episcleral hemangioma and angle malformations make this procedure extremely difficult and increase the rate of failure.

Valve implant is also a successful method for IOP management. ${ }^{68}$ In SWS, the Ahmed-type valve was shown to induce long-term decrease of IOP by improving aqueous humor outflow. ${ }^{69}$ On the other hand, the use of the Molteno tube showed an unfavorable outcome due to an elevated complication rate in children with SWS. ${ }^{70}$

Two studies reported that Ex-Press ${ }^{\circledR}$ valve was successfully implanted in children with SWS as an elective surgical procedure, ${ }^{71}$ and in the other case, 10 days prior to performing trabeculectomy..$^{72}$ On the other hand, the use of the Ex-Press ${ }^{\circledR}$ glaucoma implant in another child with SWS was complicated by choroidal detachment, which resolved with medical therapy. Lastly, it is worth mentioning that cyclocryotherapy has been used successfully in patients with SWS and buphthalmos in combination with topical antiglaucoma therapy ${ }^{73}$ or trabeculectomy. ${ }^{74}$ Nevertheless, cyclocryotherapy can be burdened by severe complications such as hypotony and phthisis bulbi. ${ }^{74}$ Unfortunately, sometimes, even with medical and/or surgical treatment glaucoma leads to severe visual field damage, visual acuity loss, and optic nerve atrophy; only rehabilitation methods can help in improving the quality of life of these patients. ${ }^{75-77}$

\section{Treatment of other ocular manifestations}

Facial PWSs can be successfully treated by laser. Better esthetic results are achieved when treating the lesions localized on the central forehead rather than the lesions on the central face. To obtain better results, PWS should be treated early since there is a tendency to thickening and nodular transformation with aging. ${ }^{78}$

Laser treatment should be superficial in order to avoid potential complications related to a decrease of brain venous outflow through PWS vessels, potentially leading to cerebral venous deterioration, choroidal vessel dilatation, retinal exudative detachment, and increase in IOP. ${ }^{7}$ Therefore, deep photocoagulation and debulking surgery should be avoided in the treatment of PWS.?

As previously described, visual loss in SWS patients is mainly related to glaucoma development, but choroidal hemangiomas may also lead to visual impairment thorough exudative retinal detachment and macular edema. The treatment of exudative hemangioma complications is aimed at destructing the tumor or at least at decreasing tumor leakage. ${ }^{79}$ Several treatments have been proposed including photocoagulation, photodynamic therapy (PDT), external beam radiotherapy, brachytherapy, and anti-vascular endothelial growth factor (VEGF). The scopes of these methods are to reduce tumor size, induce vessel atrophy, close leaking vessels, and induce inhibition of VEGF to ultimately diminish subretinal fluid, which causes increased retinal and macular thickness as observed with optical coherence tomography. ${ }^{80-82}$

Confluent photocoagulation causing destruction of the tumor has been considered as the most effective treatment in reducing leakage.$^{83}$ However, several complications can be observed following intense photocoagulative treatment, leading to the proposal of an alternative, less invasive laser procedure, such as grid treatment, that is safer but has a higher recurrence of subretinal fluid accumulation. ${ }^{84,85}$

PDT is theoretically the most indicated procedure to treat choroidal hemangiomas, inducing vessel atrophy and reducing leakage. ${ }^{66}$ However, currently, only a few cases of diffuse choroidal hemangioma have been treated with PDT, probably due to the risk of inducing scarring and pigmentary changes of the fovea. ${ }^{86}$

In case of diffuse choroidal hemangioma complicated by serous retinal detachment, an alternative treatment is external beam radiotherapy. ${ }^{87,88}$ Clinical improvement 
has been observed months following the first application but recurrence frequently occurs. Repeated applications should be carefully evaluated since they can induce several complications such as cataract, neuropathy, and radiation retinopathy. ${ }^{87}$ Exudative retinal detachment related to choroidal hemangiomas has also been successfully treated using brachytherapy with cobalt-60 and ruthenium-106. ${ }^{89-92}$ Intravitreal injection of pegaptanib (an anti-VEGF) has also been described in one SWS patient with exudative retinal detachment with satisfactory results. ${ }^{93,94}$

\section{Conclusion}

Glaucoma is the most common ocular complication in SWS. The most frequent form is congenital glaucoma, but it can also occur in children and adults, making careful ophthalmic follow-up of SWS patients mandatory. Indeed, glaucoma secondary to SWS is a challenging disease due to its early development and poor response to standard medical treatment.

Surgery is frequently required to obtain long-term control of IOP in order to avoid visual function loss. However, several severe complications related to surgical procedures have been described in these patients, including choroidal effusion, expulsive hemorrhage, and exudative retinal detachment. Moreover, in SWS, the surgical success rate is the lowest among secondary glaucomas, since surgical failure, uncontrolled IOP, and low vision outcomes have been frequently reported. ${ }^{45,60,61}$ To date, despite the wide range of available medical and surgical approaches to treat both the congenital and late-onset forms of glaucoma, the development of this ocular complication still represents the worst prognostic factor for vision loss in SWS patients.

Choroidal hemangiomas are present in $20 \%-70 \%$ of cases, and the choroid may become significantly thickened and can be associated with an increased risk of glaucoma development. ${ }^{29}$ Choroidal hemangiomas may be asymptomatic; however, severe forms may lead to visual impairment thorough exudative retinal detachment and macular edema. The treatment of exudative complications is aimed at destructing the tumor or at least at decreasing tumor leakage.

\section{Disclosure}

The authors report no conflicts of interest in this work.

\section{References}

1. Brouwer B, van der Hoeve J, Mahoney W. A fourth type of phakomatosis: Sturge Weber syndrome. Verh k Akad Wet Amst. 1937;36:1.

2. Hogan MJ, Zimmerman LE. Ophthalmic Pathology: An Atlas and Textbook. 2nd ed. Philadelphia: WB Saunders; 1962:58.

3. Aita JA. Neurocutaneous Diseases. Springfield (IL): Charles C Thomas; 1966.
4. Recupero SM, Abdolrahimzadeh S, Lepore GF, et al. L'apparato oculare nelle sindromi neurocutan [The ocular apparatus in neurocutaneous syndromes]. Roma: Verduci Editore; 2004. Italian.

5. Sami D, Vivian A, Taylor D, Saunders D. The phakomatoses. In: Duane's Opththalmology. 2006;5(36).

6. Di Rocco C, Tamburrini G. Sturge-Weber syndrome. Childs Nerv Syst. 2006;22:909-921.

7. Parsa CF. Focal venous hypertension as a pathophysiologic mechanism for tissue hypertrophy, port-wine stains, the Sturge-Weber syndrome, and related disorders: proof of concept with novel hypothesis for underlying etiological cause (an American ophthalmological society thesis). Trans Am Ophthalmol Soc. 2013;111:180-207.

8. Van der Hoeve J. The Doyne Memorial lecture: eye symptoms in the phakomatoses. Trans Opthalmol Soc U K. 1932;52:380.

9. Comi AM, Mehta P, Hatfield LA, Dowling MM. Sturge-Weber syndrome associated with other abnormalities: a medical record and literature review. Arch Neurol. 2005;62:1924-1927.

10. Lee CW, Choi DY, Oh YG, Yoon HS, Kim JD. An infantile case of Sturge-Weber syndrome in association with Klippel-Trenaunay-Weber syndrome and phakomatosis pigmentovascularis. J Korean Med Sci. 2005;20:1082-1084.

11. Sonmez FM, Aksoy A, Sari A, Erpolat S, Ozkaya AK. Phacomatosis pigmentovascularis type IIB associated with Sturge-Weber syndrome: a case report and review of the literature. Genet Couns. 2013; 24:247-250.

12. Recupero SM, Abdolrahimzadeh S, DeDominicis M, Mollo R. SturgeWeber syndrome associated with nevus of Ota. Eye (Lond). 1998;12: 212-213.

13. Abdolrahimzadeh S, Scavella V, Felli L, et al. Ophthalmic alterations in the Sturge Weber syndrome, Klippel Trenaunay syndrome and the phakomatosis pigmentovascularis: an independent group of conditions? Biomed Res Int. 2015;Article ID 786519:11 pages.

14. Happle R. Lethal genes surviving by mosaicism: a possible explanation for sporadic birth defects involving the skin. J Am Acad Dermatol. 1987;16:899-906.

15. Shirley MD, Tang H, Gallione CJ, et al. Sturge-Weber syndrome and port wine stains caused by somatic mutation in GNAQ. N Engl J Med. 2013;368:1971-1979.

16. Zaroff CM, Isaacs K. Neurocutaneous syndromes: behavioral features. Epilepsy Behav. 2005;7:133-142.

17. Waelchli R, Aylett SE, Robinson K, et al. New vascular classification of port-wine stains: imporoving prediction. Br J Dermatol. 2014;171: $861-867$.

18. Norman MG, Schoene WC. The ultrastructure of Sturge-Weber disease. Acta Neuropathol. 1977;37:199-205.

19. Baselga E. Sturge-Weber syndrome. Semin Cutan Med Surg. 2004; 23:87-98.

20. Roach ES. Neurocutaneous syndromes. Pediatr Clin North Am. 1992; 39(4):591-620.

21. Sinawat S, Auvichayapat N, Auvichayapat P, Yospaiboon Y, Sinawat S. 12-year retrospective study of Sturge-Weber syndrome and literature review. J Med Assoc Thai. 2014;97(7):742-750.

22. Mwinula JH, Sagawa T, Tawara A, Inomata H. Anterior chamber angle vascularization in Sturge-Weber syndrome. Graefes Arch Clin Exp Ophthalmol. 1994;232:387-391.

23. Sujansky E, Conradi S. Sturge-Weber syndrome: age of onset of seizures and glaucoma and the prognosis for affected children. J Child Neurol. $1995 ; 10: 49$

24. Sullivan TJ, Clarke MP, Morin JD. The ocular manifestations of the Sturge-Weber syndrome. J Pediatr Ophthalmol Strabismus. 1992;29:349.

25. Maruyama I, Ohguro H, Nakazawa M. A case of acute angle-closure glaucoma secondary to posterior scleritis in patient with Sturge-Weber syndrome. Jpn J Ophthalmol. 2002;46:74-77.

26. Ikeda N, Ikeda T, Nagata M, Mimura O. Pathogenesis of transient high myopia after blunt eye trauma. Ophthalmology. 2002;109:501-507.

27. Cruciani F, Lorenzatti M, Nazzarro V, Abdolrahimzadeh S. Bilateral acute angle closure glaucoma and myopia induced by topiramate. Clin Ter. 2009;160:215-216. 
28. Boniuk M. Hemangioma of the choroids. A clinicopathologic study of 71 cases and a review of the literature. Surv Ophthalmol. 1976;20: 415-431.

29. Arora KS, Quigley HA, Comi AM, et al. Increased choroidal thickness in patients with Sturge-Weber syndrome. JAMA Ophthalmol. 2013; 131:1216-1219.

30. Singh AD, Kaiser PK, Sears JE. Choroidal hemangioma. Ophthalmol Clin North Am. 2005;18:151-161.

31. Shields JA, Shields CL. Vascular tumors of the retina and optic nerve. In: Shields JA, Shields CL, editors. Atlas of Intraocular Tumors. Philadelphia: Lippincott Williams \& Wilkins; 1999:260-263.

32. Topcu-Yilmaz P, Kasim B, Kiratli H. Investigation of retinal nerve fiber layer thickness in patients with neurofibromatosis-1. Jpn J Ophthalmol. 2014;88:172176.

33. Abdolrahimzadeh S, Felli L, Plateroti AM, Perdicchi A, Contestabile MT, Recupero SM. Spectral domain optical coherence tomography evidence of retinal nerve fibre layer and ganglion cell loss in adult patients with neurofibromatosis type 1. Retina. 2016; 36:75-81.

34. Lee J, Kong M, Kee C. Comparison of visual field progression between relatively low and high intraocular pressure groups in normal tension glaucoma patients. J Glaucoma. 2014;23:553-560.

35. Nouri-Mahdavi K, Caprioli J. Measuring rates of structural and functional changes in glaucoma. Br J Ophthalmol. 2015;99: 893-898.

36. Recupero SM, Contestabile MT, Taverniti L, et al. Open-angle glaucoma: variations in the intraocular pressure after visual field examination. J Glaucoma. 2003;12:114-118.

37. Contestabile MT, Perdicchi A, Amodeo S, Recupero V, Recupero SM. The influence of learning effect on frequency doubling technology perimetry (Matrix). J Glaucoma. 2007;16:297-301.

38. Abdolrahimzadeh S, Felli L, Plateroti R, et al. Morphological and vasculature features of the choroid and associated choroid-retinal thickness alterations in neurofibromatosis type 1. Br J Ophthalmol. 2015;99: 789-793.

39. Doucette LP, Rasnitsyn A, Seifi M, Walter MA. The interactions of genes, age, and environment in glaucoma patholgenesis. Surv Ophthalmol. 2015;60:310-326.

40. Abdolrahimzadeh S, Fameli V, Mollo R, et al. Rare diseases leading to childhood glaucoma: epidemiology, pathophysiogenesis and management. Biomed Res Int. 2015;2015:781294.

41. Izzotti A, Saccà SC, Bagnis A, Recupero SM. Glaucoma and Helicobacter pylori infection: correlations and controversies. Brit J Ophthalmol. 2009;93:1420-1427.

42. Phelps CD. The pathogenesis of glaucoma in Sturge-Weber syndrome. Ophthalmology. 1978;85:276-286.

43. Weiss DI. Dual origin of glaucoma in encephalotrigeminal haemangiomatosis. Trans Ophthalmol Soc U K. 1973;93:477.

44. Basler L, Sowka J. Sturge-Weber syndrome and glaucoma. Optometry. 2011;82:306-309.

45. Sharan S, Swamy B, Taranath DA, et al. Port-wine vascular malformations and glaucoma risk in Sturge-Weber syndrome. J AAPOS. 2009; 13:374-378.

46. Cibis GW, Tripathi RC, Tripathi BJ. Glaucoma in Sturge-Weber syndrome. Ophthalmology. 1984;91:1061-1071.

47. Shiau T, Armogan N, Yan DB, Thomson HG, Levin AV. The role of episcleral venous pressure in glaucoma associated with Sturge-Weber syndrome. J AAPOS. 2012;16:61-64.

48. Neely D, Harris A, Siesky B, et al. Color Doppler imaging of retrobulbar hemodynamics in Sturge-Weber syndrome-associated glaucoma. Eur J Ophthalmol. 2008;18:172-176.

49. Conway M, Hosking SL. Investigation of ocular hemodynamics in Sturge-Weber syndrome. Optom Vis Sci. 2012;89:922-928.

50. Tannous Z, Rubeiz N, Kibbi AG. Vascular anomalies: portwine stains and hemangiomas. J Cutan Pathol. 2010;37:88-95.

51. Moore DB, Reck SD, Chen PP. Angle closure glaucoma associated with ectopia lentis in a patient with Sturge-Weber syndrome. Eye (Lond). 2011;25:1235-1236.
52. Lambiase A, Mantelli F, Mannino G, Recupero SM. An atypical case of glaucoma in Sturge Weber syndrome. Eur J Ophthalmol. 2015. 21;25(6):e103-105. [Epub ahead of print].

53. Mannino G, Malagola R, Abdolrahimzadeh S, et al. Ultrasound biomicroscopy of the peripheral retina and the ciliary body in degenerative retinoschisis associated with pars plana cysts. Br J Ophthalmol. 2001;85: 976-982.

54. Ong T, Chia A, Nischal KK. Latanoprost in port wine stain related paediatric glaucoma. Br J Ophthalmol. 2003;87:1091-1093.

55. Yang CB, Freedman SF, Myers JS, et al. Use of latanoprost in the treatment of glaucoma associated with Sturge-Weber syndrome. Am J Ophthalmol. 1998;126:600-602.

56. Ebert EM, Boger WP, Albert D. Phacomatoses. In: Albert DM, Jakobiec FA, editors. Principles and Practice of Ophthalmology. 2nd Edition. Volume 6. Philadelphia, PA, USA: Saunders; 2000:5131-5135.

57. Wygnanski-Jaffe T, Spierer A, Melamed S, Ben-Zion I. The effect of oral propranolol on intraocular pressure in infants with Sturge-Weber syndrome glaucoma. Eur J Ophthalmol. 2015;25(2):134-136.

58. Léauté-Labrèze C, Dumas de la Roque E, Hubiche T, Boralevi F, Taieb A. Propranolol for severe hemangiomas of infancy. NEngl J Med. 2008;358:2649-2651.

59. Zvulunov A, McCuaig C, Frieden IJ, et al. Oral propranolol therapy for infantile hemangiomas beyond the proliferation phase: a multicenter retrospective study. Pediatr Dermatol. 2011;28:94-98.

60. Saltzmann RM, Reinecke S, Lin X, Cavanagh HD, Whitson JT. Longterm outcomes of a pseudo 360-degree trabeculotomy ab externo technique for congenital glaucoma at children's medical center. Clin Ophthalmol. 2012;6:689-698.

61. Board RJ, Shields MB. Combined trabeculotomy-trabeculectomy for the management of glaucoma associated with Sturge-Weber syndrome. Ophthalmic Surg. 1981;12:813-817.

62. Agarwal HC, Sandramouli S, Sihota R, Sood NN. Sturge-Weber syndrome: management of glaucoma with combined trabeculotomytrabeculectomy. Ophthalmic Surg. 1993;24:399-402.

63. Shihab ZM, Kristan RW. Recurrent intraoperative choroidal effusion in Sturge-Weber syndrome. J Pediatr Ophthalmol Strabismus. 1983;20: $250-252$.

64. Rao A, Srinivasan G, Gupta V. Anomalous vessels over a trabeculectomy bleb in Sturge-Weber syndrome. Digit J Ophthalmol. 2011; $17(1): 1-2$

65. Mandal AK. Primary combined trabeculotomy-trabeculectomy for the management of glaucoma associated with Sturge-Weber syndrome. Ophthalmology. 1999;106:1621-1627.

66. Patrianakos TD, Nagao K, Walton DS. Surgical management of glaucoma with the Sturge-Weber syndrome. Int Ophthalmol Clin. 2008;48:63-78.

67. Audren F, Abitbol O, Dureau P, et al. Non-penetrating deep sclerectomy for glaucoma associated with Sturge-Weber syndrome. Acta Ophthalmol Scand. 2006;84:656-660.

68. Celebi S, Alagoz G, Aykan U. Ocular findings in Sturge-Weber syndrome. Eur J Ophthalmol. 2000;10:239-243.

69. Hamush NG, Coleman AL, Wilson MR. Ahmed glaucoma valve implant for management of glaucoma in Sturge-Weber syndrome. Am J Ophthalmol. 1999;128:758-760.

70. Amini H, Razeghinejad MR, Esfandiarpour B. Primary single-plate Molteno tube implantation for management of glaucoma in children with Sturge-Weber syndrome. Int Ophthalmol. 2007;27:345-350.

71. Naranjo-Bonilla P, Giménez-Gómez R, Gallardo-Galera JM. Ex-Press ${ }^{\circledR}$ implant in glaucoma and Sturge Weber syndrome. Arch Soc Esp Oftalmol. 2014;89(12):508-509.

72. Elgin U, Simsek T, Batman A. Use of the ex-press miniature glaucoma implant in a child with Sturge-Weber syndrome. J Pediatr Ophthalmol Strabismus. 2007;44(4):248-250.

73. Van Emelen C, Goethals M, Dralands L, Casteels I. Treatment of glaucoma in children with Sturge-Weber syndrome. J Pediatr Ophthalmol Strabismus. 2000;37:29-34.

74. Caprioli J, Strang SL, Spaeth GL, Poryzees EH. Cyclocryotherapy in the treatment of advanced glaucoma. Ophthalmology. 1985;92:947-954. 
75. Sabel BA, Gudlin J. Vision restoration training for glaucoma: a randomized clinical trial. JAMA Ophthalmol. 2014;132:381-389.

76. Contestabile MT, Recupero SM, Suppressa F, et al. A new method of biofeedback in the management of low vision. Eye (Lond). 2002;16(4): $472-480$.

77. Hirasawa H, Murata H, Mayama C, et al. Evaluation of various machine learning methods to predict vision-related quality of life from visual field data and visual acuity in adult patients with glaucoma. Br J Ophthalmol. 2014;98:1230-1235.

78. Thomas-Sohl KA, Vaslow DF, Maria BL. Sturge-Weber syndrome: a review. Pediatr Neurol. 2004;30:303-310.

79. Madreperla SA. Choroidal hemangioma treated with photodynamic therapy using verteporfirin. Arch Ophthalmol. 2001;119: 1606-1610.

80. Shields CL, Manalac J, Das C, et al. Review of spectral domain enhanced depth imaging optical coherence tomography of tumors of the retinal and retinal pigment epithelium in children and adults. Indian J Opthalmol. 2015;63:128-132.

81. Gharbiya M, Cruciani F, Cuozzo G, et al. Macular thickness changes evaluated with spectral domain optical coherence tomography after uncomplicated phacoemulsification. Eye. 2013;27:605-611.

82. Baltmr A, Lightman S, Tomkins-Netzer O. Examining the choroid in ocular inflammation: a focus on enhanced depth imaging. JOphthalmol. 2014;2014:459136. Epub 2014 Jun 16.

83. Gass JDM. Stereoscopic Atlas of Macular Diseases: Diagnosis and Treatment. 2nd ed. St Louis: Mosby; 1977:130-135,393.

84. Augsburger JJ, Shields JA, Moffat KP. Circumbscribed choroidal hemangiomas: long-term visual prognosis. Retina. 1981;1:56-61.
85. Anand R, Augsburger JJ, Shields JA. Circumscribed choroidal hemangiomas. Arch Ophthalmol. 1989;107:1338-1342.

86. Tsipursky MS, Golchet PR, Jampol LM. Photodynamic therapy of choroidal hemangioma in Sturge-Weber syndrome, with a review of treatments for diffuse and circumscribed choroidal hemangiomas. Surv Ophthalmol. 2011;56:68-85.

87. Ritland JS, Eide N, Tausjø J. External beam irradiation therapy for choroidal haemangiomas. Visual and anatomical results after a dose of 20 to 25 Gy. Acta Ophthalmol Scand. 2001;79:184-186.

88. Gottlieb JL, Murray TG, Gass JDM. Low dose external beam irradiation for bilateral diffuse choroidal hemangioma. Arch Ophthalmol. 1998; $116: 815-817$

89. MacLean L, Maumenee E. Hemangioma of the choroid. Am J Ophthalmol. 1960;50:3-11.

90. Zografos L, Bercher L, Chamot L, et al. Cobalt-60 treatment of choroidal hemangiomas. Am J Ophthalmol. 1996;121:190-199.

91. Murthy R, Hanovar SG, Naik M, et al. Ruthenium-106 plaque brachytherapy for the treatment of diffuse choroidal haemangioma in Sturge-Weber syndrome. Indian J Ophthalmol. 2005;53:274-275.

92. Kubicka-Trzaska A, Kobylarz J, Romanowska-Dixon B. Ruthenium106 plaque therapy for diffuse choroidal hemangioma in Sturge-Weber syndrome. Case Rep Ophthalmol Med. 2011;2011:785686.

93. Paulus YM, Jain A, Moshfeghi DM. Resolution of persistent exudative retinal detachment in a case of Sturge-Weber syndrome with AntiVEGF administration. Ocul Immunol Inflamm. 2009;17:292-294.

94. Lambiase A, Abdolrahimzadeh S, Recupero SM. An update on intravitreal implants in use for eye disorders. Drugs Today. 2014;50: 239-249.
Clinical Ophthalmology

\section{Publish your work in this journal}

Clinical Ophthalmology is an international, peer-reviewed journal covering all subspecialties within ophthalmology. Key topics include: Optometry; Visual science; Pharmacology and drug therapy in eye diseases; Basic Sciences; Primary and Secondary eye care; Patient Safety and Quality of Care Improvements. This journal is indexed on Submit your manuscript here: http://www.dovepress.com/clinical-ophthalmology-journal

\section{Dovepress}

PubMed Central and CAS, and is the official journal of The Society of Clinical Ophthalmology (SCO). The manuscript management system is completely online and includes a very quick and fair peer-review system, which is all easy to use. Visit http://www.dovepress.com/ testimonials.php to read real quotes from published authors. 